\title{
Activation of Src Family Tyrosine Kinases by Ferric Ions
}

Graham S. Baldwin ${ }^{1}$, Daisy Sio-Seng Lio ${ }^{2}$, Audrey Ferrand ${ }^{1}$, Bruno Catimel ${ }^{3}$, B. Philip Shehan $^{1}$, Raymond S. Norton ${ }^{4 \S}$ and Heung-Chin Cheng ${ }^{2}$.

${ }^{1}$ The University of Melbourne Department of Surgery, Austin Health, Heidelberg, Victoria, Australia,

${ }^{2}$ Department of Biochemistry and Molecular Biology, Bio21 Molecular Science and Biotechnology Institute, University of Melbourne, Parkville, Victoria, Australia, ${ }^{3}$ Ludwig Institute for Cancer Research, Melbourne Branch, Austin Hospital, Heidelberg, Victoria, Australia, ${ }^{4}$ The Walter and Eliza Hall Institute of Medical Research, Parkville, Victoria, Australia.

\section{Corresponding Author:}

Professor Graham S. Baldwin, Department of Surgery, Austin Health, Studley Road, Heidelberg, Victoria 3084, Australia. Tel: 613-9496-5592; Fax: 613-9458-1650; E-mail: grahamsb@unimelb.edu.au

Running Title: Ferric Ions Activate Src Family Tyrosine Kinases

Abbreviations: CCK, cholecystokinin; CDK2, cyclin-dependent kinase 2; DMEM, Dulbecco’s Modified Eagle Medium; HBS, HEPES buffered saline; SFK, Src-family tyrosine kinases.

Keywords: calcium, kinase, ferric, iron, phosphotyrosine.

${ }^{\S}$ RSN present address: Medicinal Chemistry and Drug Action, Monash Institute of Pharmaceutical Sciences, Monash University, Parkville 3052. Australia. 


\section{Abstract}

The Src-family tyrosine kinases (SFKs) are oncogenic enzymes that contribute to the initiation and progression of many types of cancer. In normal cells, SFKs are kept in an inactive state mainly by phosphorylation of a consensus regulatory tyrosine near the C-terminus ( $\mathrm{Tyr}^{530}$ in the SFK c-Src). As recent data indicate that tyrosine modification enhances binding of metal ions, the hypothesis that SFKs might be regulated by metal ions was investigated. The c-Src C-terminal peptide bound two $\mathrm{Fe}^{3+}$ ions with affinities at $\mathrm{pH} 4.0$ of 33 and $252 \mu \mathrm{M}$, and phosphorylation increased the affinities at least 10-fold to 1.4 and $23 \mu \mathrm{M}$, as measured by absorbance spectroscopy. The corresponding phosphorylated peptide from the SFK Lyn bound two $\mathrm{Fe}^{3+}$ ions with much higher affinities (1.2 $\mathrm{pM}$ and $\left.160 \mathrm{nM}\right)$ than the Src C-terminal peptide. Furthermore, when Lyn or Hck kinases, which had been stabilised in the inactive state by phosphorylation of the $\mathrm{C}$-terminal regulatory tyrosine, were incubated with $\mathrm{Fe}^{3+}$ ions, a significant enhancement of kinase activity was observed. In contrast Lyn or Hck kinases in the unphosphorylated active state were significantly inhibited by $\mathrm{Fe}^{3+}$ ions. These results suggest that $\mathrm{Fe}^{3+}$ ions can regulate SFK activity by binding to the phosphorylated C-terminal regulatory tyrosine. 


\section{Introduction}

The ability to phosphorylate tyrosine residues is an intrinsic property of a very important family of eukaryotic enzymes, the tyrosine kinases [1]. Such phosphorylation permits precise control of various signalling pathways, not only by allowing the activation or inhibition of certain target proteins, but also by promoting interaction between different components of the pathways. Thus, tyrosine kinases are actively involved in the regulation of cellular metabolism, differentiation, adhesion, migration, proliferation and apoptosis [2]. In a normal quiescent cell, the activity of tyrosine kinases is relatively low and very tightly regulated, but is often increased in disease states.

Metal ions are essential components of many biological systems, and play a crucial role in many enzyme reactions [3]. The octapeptide hormone cholecystokinin $\left(\mathrm{CCK}_{8}\right)$, which occurs naturally in both sulphated and unsulphated forms, has been utilized as a model to investigate the effect of tyrosine phosphorylation or sulphation on metal ion binding [4]. Tyrosine modification increased the stoichiometry of $\mathrm{Fe}^{3+}$ ion binding from 1 to 2 , without greatly affecting the affinity $(0.6-2.8 \mu \mathrm{M}$ at $\mathrm{pH}$ 6.5), as measured by changes in absorbance and fluorescence emission. Binding of $\mathrm{Ca}^{2+}, \mathrm{Zn}^{2+}$ or $\mathrm{Bi}^{3+}$ ions to tyrosine phosphorylated-CCK 8 did not cause any change in absorbance, but substantially increased the change in absorbance on subsequent addition of $\mathrm{Fe}^{3+}$ ions. These results demonstrated that tyrosine modification might increase the affinity of metal ions for peptides, and implied that metal ions might directly regulate many signalling pathways.

In a subsequent study the effect on metal binding of phosphorylation of neighbouring $\mathrm{Thr}^{14}$ and $\mathrm{Tyr}^{15}$ residues in synthetic peptides based on the N-terminal sequence of the cyclin-dependent kinase 2 (CDK2) was investigated [5]. Although binding of $\mathrm{Fe}^{3+}$ ions to the un-phosphorylated peptide was not detected, both of the singly-phosphorylated peptides and the doubly-phosphorylated peptide bound two $\mathrm{Fe}^{3+}$ ions. The observation that several iron-selective chelators reduced CDK2 activity in HEK293 cells suggested that iron binding might well be necessary for CDK2 activity in vivo [6]. 
The tyrosine kinase c-Src, originally identified by its close homology to the oncogene of the Rous avian sarcoma virus, is the prototype of the Src-family tyrosine kinases (SFKs), which play critical roles in intracellular signalling [7-9]. For example, the related tyrosine kinase Lyn is expressed in neural tissue, myeloid cells and B lymphocytes, in which it is a key mediator of cell activation [10]. The activity of Src family members is controlled by modification of a C-terminal tyrosine ( $\mathrm{Y}^{530}$ in human c-Src, $\mathrm{Y}^{508}$ in human Lyn and $\mathrm{Y}^{522}$ in human Hck (Figure 1)) which, when phosphorylated, binds to the $\mathrm{SH} 2$ domain at the N-terminus of the same molecule to stabilise the inactive conformation of the kinase domain $[11,12]$. The interactions between phosphotyrosine-containing peptides and metal ions described above suggested the possibility that binding of $\mathrm{Fe}^{3+}$ ions to phosphorylated $\mathrm{Y}^{530}$ of $\mathrm{Src}$ might disrupt the intramolecular interaction with the $\mathrm{SH} 2$ domain and hence enhance Src kinase activity.

In this study, the hypothesis that $\mathrm{Fe}^{3+}$ ions bind to and activate SFKs has been tested by both biophysical and biochemical approaches. Binding of $\mathrm{Fe}^{3+}$ ions to synthetic peptides derived from the Cterminal regulatory region of SFKs was measured by absorption and NMR spectroscopy. The effect of $\mathrm{Fe}^{3+}$ ions on the structure and activity of Lyn and Hck, in both the active unphosphorylated conformation and the inactive conformation stabilized by constitutive phosphorylation of the Cterminal regulatory tyrosine, was measured by surface plasmon resonance and by in vitro kinase assay. 


\section{Materials and Methods}

\subsection{Peptides.}

$\mathrm{Y}^{530}$-SrcC and $\mathrm{F}^{530}$-SrcC peptides were synthesised by the Joint Proteomics Research Laboratory, Ludwig Institute for Cancer Research, Parkville, Australia. Tyrosine phosphorylated $\mathrm{pY}^{530}-\mathrm{SrcC}$ peptide was from Mimotopes (Clayton, Australia). Tyrosine phosphorylated $\mathrm{pY}^{508}$-LynC peptide and the $\left[\right.$ Lys $^{19}$ ]Cdc2-(6-20) peptide (KVEKIGEGTYGVVKK) were synthesized by Fmoc-based chemistry as described previously $[13,14]$. The purity of all peptides was $>95 \%$ as assessed by reverse phase HPLC.

\subsection{Absorption spectroscopy.}

Absorption spectra of peptides $(40 \mu \mathrm{M}$ in $10 \mathrm{mM} \mathrm{Na}$ acetate $(\mathrm{pH} 4.0)$ or $10 \mathrm{mM}$ Na PIPES (pH 6.5) containing $100 \mathrm{mM} \mathrm{NaCl}$ and $0.005 \%$ Tween 20) in the presence of increasing concentrations of ferric ions were measured against a buffer blank, in $1 \mathrm{ml}$ quartz cuvettes thermostatted at $298 \mathrm{~K}$, with a Cary 5 spectrophotometer (Varian, Mulgrave, Australia). Data (expressed as means \pm S.E.M.) for the independent binding of ferric ions to peptides were fitted to one-site or two-site ordered models with the program BioEqs $[15,16]$.

\subsection{NMR spectroscopy.}

$\mathrm{Y}^{530}-\mathrm{SrcC}$ and $\mathrm{pY}^{530}-\mathrm{SrcC}$ were dissolved in $90 \% \mathrm{H}_{2} \mathrm{O} / 10 \%{ }^{2} \mathrm{H}_{2} \mathrm{O}$. The $\mathrm{pH}$ was adjusted to 4.0 or 6.5 with $\mathrm{NaO}^{2} \mathrm{H} /{ }^{2} \mathrm{HCl}$, and $\mathrm{pH}$ readings are uncorrected for the presence of ${ }^{2} \mathrm{H}_{2} \mathrm{O}$. ${ }^{1} \mathrm{H}$ NMR spectra were recorded at $298 \mathrm{~K}$ on Bruker Avance 500 or 600 spectrometers, and referenced to 2,2-dimethyl-2silapentane-5-sulphonate at $0 \mathrm{ppm}$ via the chemical shift of the $\mathrm{H}_{2} \mathrm{O}$ resonance at $4.77 \mathrm{ppm}$, as described previously [17]. 


\subsection{Measurement of calcium binding.}

The change in free $\left[\mathrm{Ca}^{2+}\right]$ during addition of aliquots of calcium chloride to peptides $(15-40 \mu \mathrm{M})$ in $10 \mathrm{mM} \mathrm{Na}^{+}$PIPES, pH 6.5, $100 \mathrm{mM} \mathrm{NaCl}, 0.005 \%$ Tween 20, 0.4\% DMSO was measured at $293 \mathrm{~K}$ with a uniPROBE calcium-selective electrode (TPS, Springwood, Australia) connected to a Hanna $8521 \mathrm{pH}$ meter (Hanna Instruments, Tullamarine, Australia), as described by Park and coworkers [18]. The electrode was first calibrated with solutions of known $\left[\mathrm{Ca}^{2+}\right]$ in the range $1-1000 \mu \mathrm{M}$ in the same buffer. The concentration of $\mathrm{Ca}^{2+}$ ion bound to each peptide was calculated by subtraction of the free $\left[\mathrm{Ca}^{2+}\right]$ from the total added $\left[\mathrm{Ca}^{2+}\right]$.

\subsection{Preparation of Lyn or Hck kinase.}

Recombinant mouse Lyn or Hck kinase stoichiometrically phosphorylated at the C-terminal regulatory tyrosine ( $\mathrm{Y}^{508}$ for Lyn, $\mathrm{Y}^{522}$ for Hck) was generated by co-expression with the recombinant C-terminal Src Kinase CSK in Sf9 cells as described in our previous reports [19, 20]. Briefly, Sf9 cells $\left(1 \mathrm{~L}, 0.7 \times 10^{6}-1 \times 10^{6}\right.$ cells $\left./ \mathrm{ml}\right)$ were co-infected with recombinant Lyn or Hck baculovirus and CSK baculovirus at a multiplicity of infection $\geq 2$. The cells were harvested $50 \mathrm{~h}$ after infection, and the recombinant Lyn [19] or Hck [20] was purified to $\geq 90 \%$ purity by sequential chromatography on DEAE, hydroxylapatite, MonoS cation exchange and MonoQ anion exchange columns as described previously. To remove the active unphosphorylated and autophosphorylated Lyn and Hck, the enzyme preparations were chromatographed on a column containing pYEEI-gel [KKTHQEEEEPQ(pY)EEIPIYL covalently attached to Affigel-10 (BioRad)], which selectively bound unphosphorylated Lyn and Hck and autophosphorylated Lyn and Hck [20, 21], but not pY ${ }^{508}$-Lyn or $\mathrm{pY}^{522}$-Hck [19]. Briefly, the enzyme preparations were applied to a pYEEI-gel column (1 ml packed volume, loading density $=0.85 \mu \mathrm{mol}$ of $\mathrm{pYEEI}$ peptide per $\mathrm{ml}$ of packed gel) pre-equilibrated with the affinity column buffer (25 mM Hepes pH 7.0, 0.1\% NP-40, 10\% glycerol, $1 \mathrm{mM}$ EDTA, $0.2 \mathrm{mg} / \mathrm{ml}$ 
benzamidine, $10 \mathrm{mM} \beta$-glycerophosphate, $0.1 \mathrm{mg} / \mathrm{ml}$ PMSF, $1 \mathrm{mM}$ DTT, $0.5 \mathrm{mM} \mathrm{Na} \mathrm{VO}_{4}$ and $50 \mathrm{mM}$ $\mathrm{NaF}$ ). The unbound fractions, containing solely or predominantly $\mathrm{pY}^{508}$-Lyn or $\mathrm{pY}^{522}-\mathrm{Hck}$, were analyzed by Western blotting with anti-Lyn-pY ${ }^{508}$ antibody (Cell Signaling) and by mass spectrometry to assess the phosphorylation states of these proteins, and by activity assay to ascertain their activation by the SH3 domain targeting protein ligand HIV-1, as described previously [19].

\subsection{Lyn or Hck kinase assay.}

The $\left[\right.$ Lys $^{19}$ ]Cdc2-(6-20) peptide (KVEKIGEGTYGVVKK) was used as a substrate to assay Lyn or Hck kinase activity [22]. The kinase assay mixture $(25 \mu \mathrm{l})$ consisted of $0.13 \mu \mathrm{g}$ of Lyn, $0.74 \mu \mathrm{g}$ of $\mathrm{pY}^{508}$-Lyn, $0.09 \mu \mathrm{g}$ of Hck or $0.03 \mu \mathrm{g}$ of $\mathrm{pY}^{522}$-Hck, $300 \mu \mathrm{M}\left[\mathrm{Lys}^{19}\right] \mathrm{Cdc} 2-(6-20)$ peptide, and 100 $\mu \mathrm{M}\left[\gamma_{-}{ }^{32} \mathrm{P}\right] \mathrm{ATP}$, in kinase assay buffer (10 mM Na PIPES, pH 6.5, $10 \mathrm{mM} \mathrm{MgCl} 2,1 \mathrm{mM} \mathrm{MnCl} 2,50$ $\mu \mathrm{M} \mathrm{Na} \mathrm{VO}_{4}$ ), without or with $\mathrm{FeCl}_{3}$ at 10, 20, 40 and $80 \mu \mathrm{M}$. An assay mixture without Lyn or Hck kinase was used as a blank to quantify the background radioactivity. Phosphorylation was allowed to proceed at $30{ }^{\circ} \mathrm{C}$ for $20 \mathrm{~min}$ and, after termination of the reaction, the amount of phosphorylated peptide was determined as described previously [23].

\subsection{Western blotting to monitor phosphorylation state of Lyn and Hck kinases}

For Lyn kinase, $0.5 \mu \mathrm{g}$ each of the unphosphorylated Lyn or $\mathrm{pY}^{508}$-Lyn were analysed by

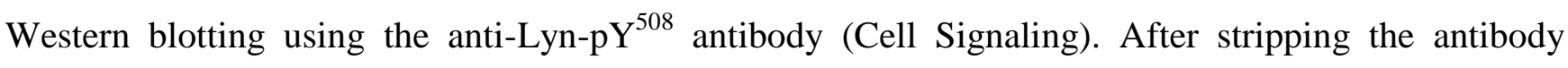
bound to the membrane, the same membrane was probed with an anti-Lyn antibody [21]. For Hck kinase, $6 \mathrm{ng}$ each of the unphosphorylated or $\mathrm{pY}^{522}$-Hck were used for Western blot analyses with the anti-Lyn-pY $\mathrm{Y}^{508}$ antibody followed by an anti-Hck antibody. Since the sequences of the C-terminal regulatory regions of Hck and Lyn differ by only one amino acid, the anti-Lyn-pY ${ }^{508}$ antibody also recognises $\mathrm{pY}^{522}$-Hck [19]. 


\subsection{Analysis of the binding of $\mathrm{pY}^{508}$-Lyn and unphosphorylated Lyn to immobilised pYEEI peptide by surface plasmon resonance}

Interaction studies between immobilized pYEEI peptide and Lyn or phospho-Lyn were conducted using a BIAcore 2000 biosensor (BIAcore, GE Healthcare). The pYEEI peptide contained the sequence of the hamster polyoma virus middle $\mathrm{T}$ antigen (THQEEEEPQ(pY)EEIPIYL) and was immobilised onto a linear polycarboxylate hydrogel (SCB HCX x-5) sensor chip (Xantec Bioanalytics, Germany) using N-ethyl-N'-dimethylaminopropyl-carbodiimide and N-hydroxysuccinimide with Hepes Buffered Saline (HBS) (10 mM Hepes, pH 7.4, containing $3.4 \mathrm{mM}$ EDTA, $0.15 \mathrm{M} \mathrm{NaCl}$ and $0.005 \%$ Tween 20) as previously described [24, 25]. A blank channel was also derivatized using the same conditions to serve as a control.

Prior to biosensor analysis, proteins were purified using micropreparative size exclusion chromatography with a Superose 12 column (PC 3.2/30) equilibrated in HBS and connected to a SMART system (GE Healthcare) [24, 25]. Proteins were quantified by UV spectroscopy using their molecular extinction coefficient at $280 \mathrm{~nm}$ calculated from their amino acid composition (http://au.expasy.org/tools/protparam.html). Samples for analysis (90 $\mu$ l) were injected over the sensor surface at a flow rate of $30 \mu \mathrm{l} / \mathrm{min}$ to minimize mass transport of analyte to the immobilized peptide. All sensorgrams were corrected by subtraction of the corresponding signal obtained when the sample was injected over a derivatised control channel. Following completion of the injection phase, the dissociation was monitored in HBS for 180 s at the same flow rate. The flow channel was regenerated with glycine (10mM; pH 2.0) prior to the next injection cycle.

Binding curves were measured quantitatively for kinetic constants using BIAEVALUATION 4.1 software. All sensorgrams were fitted with a 1/1 Langmuir model using the regions of the dissociation and association phases where Langmuir interactions appeared to be operative. Equilibrium dissociation 
constants $\left(\mathrm{K}_{\mathrm{D}}\right)$ were obtained from values of $k_{a}$ (association rate, linear with respect to plots of $\ln \mathrm{dR} / \mathrm{dt}$ versus $\mathrm{t}$ )) and $k_{d}$ (dissociation rate, fitted in the linear region for plots of $\ln \left(\mathrm{R}_{\mathrm{o}} / \mathrm{R}\right)$ versus $\left.\mathrm{t}\right)$. The goodness of fit between experimental data and fitted curves were estimated by chi-squared $\left(\chi^{2}\right)$ analysis using the equation:

$$
\chi^{2}=\frac{{ }_{1} \Sigma^{\mathrm{n}}\left(\mathrm{r}_{\mathrm{f}}-\mathrm{r}_{\mathrm{x}}\right)^{2}}{\mathrm{n}-\mathrm{p}}
$$

where $r_{f}$ is the fitted value at a given point, $r_{x}$ is the experimental value at the same point, $n$ is the number of data points and $\mathrm{p}$ is the number of degrees of freedom. To enable a comparison of the surface reactivity following the different immobilisation chemistries, the molar binding activities were calculated from the equation:

Molar binding activity $=\quad($ enzyme response $) \times($ peptide molecular weight $)$

(amount of immobilised peptide) $\times($ enzyme molecular weight $)$

\subsection{Statistics.}

Data from the lyn and hck kinase assays were analysed by one-way ANOVA with Bonferroni correction with the program Sigmastat (Jandel Scientific, San Raphael, CA). 


\section{Results}

\subsection{Phosphorylation enhances the binding of ferric ions to Src C-terminal tail peptides.}

The effect of addition of $\mathrm{Fe}^{3+}$ ions on the absorption spectrum of the Src C-terminal peptides $\mathrm{F}^{530}-\mathrm{SrcC}, \mathrm{Y}^{530}-\mathrm{SrcC}$ or $\mathrm{pY}^{530}-\mathrm{SrcC}$ (Figure 1) was first investigated at $\mathrm{pH}$ 4.0. This $\mathrm{pH}$ value was chosen in order to avoid any problems with precipitation of ferric hydroxides. The absorbance of all three peptides at $275 \mathrm{~nm}$ increased on addition of $\mathrm{Fe}^{3+}$ ions, and the increase was greatest with $\mathrm{pY}^{530}$ SrcC (Figure 2A). A two-site model, with the dissociation constants given in Table 1, gave good fits to the absorbance data for all three peptides. The c-Src C-terminal tail peptide bound two $\mathrm{Fe}^{3+}$ ions with affinities of 33 and $252 \mu \mathrm{M}$, and phosphorylation increased the affinities at least 10-fold to 1.4 and 23 $\mu \mathrm{M}$.

To assess the contribution of ionization of the phosphorylated tyrosine residue to ferric ion binding, the titration experiments were repeated at $\mathrm{pH} 6.5$, as the $\mathrm{pKa}$ of the phosphoryl group of phosphotyrosine is 5.9 [26]. At $\mathrm{pH}$ 6.5, no precipitation of iron hydroxides was observed during the course of the experiment. The observation that the absorbance did not change greatly on addition of ferric ions up to a molar ratio of 1:1 suggests that binding of the first ferric ion did not cause a major change in absorbance at this $\mathrm{pH}$ (Figure 2B). A two-site model, with the dissociation constants given in Table 1, again gave good fits to the absorbance data for all three peptides. At $\mathrm{pH} 6.5$, phosphorylation had little effect on the affinities of the Src C-terminal peptide for $\mathrm{Fe}^{3+}$ ions.

\subsection{NMR Spectroscopy.}

In an attempt to define the ligands involved in ferric ion binding, the effect of ferric ions on the NMR spectra of $\mathrm{Y}^{530}-\mathrm{SrcC}$ and $\mathrm{pY}^{530}-\mathrm{SrcC}$ was investigated. At $\mathrm{pH} 4.0$, addition of 1 or $2 \mathrm{~mol} / \mathrm{mol}$ $\mathrm{FeCl}_{3}$ resulted in no change in the resonances for $\mathrm{Y}^{530}-\mathrm{SrcC}$ (Figure 3A), apart from some line broadening and consequent loss in signal intensity due to the presence of paramagnetic ferric ions in 
solution. In contrast, addition of ferric ions resulted in significant incremental reductions in peptide signal from $\mathrm{pY}^{530}-\mathrm{SrcC}$ (Figure 3B), consistent with the formation of an insoluble $\mathrm{Fe}^{3+}-\mathrm{pY}^{530}-\mathrm{SrCC}^{3}$ complex. At pH 6.5 ferric ions were added as the citrate salt to avoid precipitation of ferric hydroxides at the higher iron concentrations required for NMR titration experiments. Although there was no change in the spectrum of $\mathrm{Y}^{530}-\mathrm{SrcC}$ on addition of ferric citrate other than some general line broadening (Figure 3C), with $\mathrm{pY}^{530}$-SrcC there were small effects on several peaks in the spectrum (Figure 3D). In particular there was a small downfield shift in the NH triplet of the sole glycine residue, to a maximum of $0.02 \mathrm{ppm}$ at $10 \mathrm{~mol} / \mathrm{mol}$ of added $\mathrm{Fe}^{3+}$ ion. As previously observed with $\mathrm{Fe}^{3+}$ ion binding to $\mathrm{pY}-\mathrm{CCK}_{8}[4]$, the absence of any significant movement or reduction in the glutamate side chain resonances was consistent with a distant interaction with the metal ion, presumably via the phosphate group, rather than with direct ligation.

\subsection{Effect of other metal ions on binding of ferric ions to $\mathrm{pY}^{\mathbf{5 3 0}}$-SrcC.}

To ascertain the specificity of ferric ion binding to $\mathrm{pY}^{530}-\mathrm{SrcC}$, the binding affinity of $\mathrm{Ca}^{2+}, \mathrm{Zn}^{2+}$ and $\mathrm{Bi}^{3+}$ to the phosphopeptide, and the effect of these ions on the binding of $\mathrm{Fe}^{3+}$ to the phosphopeptide, were measured. To determine whether or not $\mathrm{SrcC}$ and related peptides bound calcium ions as well as ferric ions, the changes in free $\left[\mathrm{Ca}^{2+}\right]$ during addition of aliquots of calcium chloride to $\mathrm{F}^{530}-\mathrm{SrcC}, \mathrm{Y}^{530}-\mathrm{SrcC}$ or $\mathrm{pY}^{530}-\mathrm{SrcC}$ were measured with a calcium-selective electrode. Although a $\mathrm{pH}$ of 6.5 was chosen to maximize the chance of detecting an interaction, no evidence of binding of calcium ions was observed for any of the peptides (data not shown).

To determine whether or not the binding of other metal ions to $\mathrm{pY}^{530}$-SrcC enhanced the binding of ferric ions, as was previously observed with tyrosine phosphorylated-CCK ${ }_{8}$ [4], the effects of prior addition of $\mathrm{Ca}^{2+}, \mathrm{Zn}^{2+}$ or $\mathrm{Bi}^{3+}$ ions on the changes in absorption spectrum of $\mathrm{pY}^{530}-\mathrm{SrcC}$ in response to $\mathrm{Fe}^{3+}$ ions were investigated. None of the above metal ions caused any increase in the absorption 
maximum at $275 \mathrm{~nm}$ at $\mathrm{pH} 4.0$ (Figure 4A-C) or at pH 6.5 (Figure 4D-F). With added $\mathrm{Ca}^{2+}$ (Figure 4D) or $\mathrm{Zn}^{2+}$ (Figure 4E), subsequent addition of ferric ions at $\mathrm{pH} 6.5$ did not cause a substantially greater increase in absorption than the increase observed in the presence of ferric ions alone. In contrast, with added $\mathrm{Bi}^{3+}$ at $\mathrm{pH} 6.5$, the increase in absorption on addition of ferric ions was well fitted by a one-site model (Figure $4 \mathrm{~F})$. The data are consistent with the conclusions that $\mathrm{Bi}^{3+}$ ions compete effectively with one of the two ferric ion binding sites, that the $\mathrm{Bi}^{3+}$ ion is bound more tightly than the $\mathrm{Fe}^{3+}$ ion, and that binding of the $\mathrm{Bi}^{3+}$ ion has no effect on peptide absorption.

\subsection{Binding of ferric ions to Lyn peptides.}

The binding of $\mathrm{Fe}^{3+}$ ions to the corresponding tyrosine-phosphorylated C-terminal peptide from the tyrosine kinase Lyn ( $\mathrm{pY}^{508}$-LynC, Figure 1) was then examined. At pH 4.0 the absorbance of $\mathrm{pY}^{508}$ LynC at $275 \mathrm{~nm}$ increased on addition of $\mathrm{Fe}^{3+}$ ions; this increase was greater, and occurred at lower ratios of ferric ion to peptide, than with $\mathrm{pY}^{530}-\mathrm{SrcC}$ (Figure 5A). A two-site model, with the dissociation constants given in Table 1 , again gave good fits to the absorbance data, although the $\mathrm{K}_{\mathrm{d}}$ values were much lower (1.2 pM and $160 \mathrm{nM})$, and the absorbance values greater, than the corresponding values for the Src peptide.

The binding of $\mathrm{Fe}^{3+}$ ions to $\mathrm{pY}^{508}$-LynC at $\mathrm{pH} 6.5$ was more difficult to interpret. The increase in absorbance at $275 \mathrm{~nm}$ was again greater than with $\mathrm{pY}^{530}-\mathrm{SrcC}$, but a decrease in absorbance was observed at higher ratios of ferric ion to peptide (Figure 5B). Since no precipitation was visible, one possible explanation is that a third binding site for $\mathrm{Fe}^{3+}$ ions exists at the higher $\mathrm{pH}$, but in fact a threesite model gave a worse fit to the data than a two-site model.

\subsection{Ferric ions stimulate the kinase activity of Lyn and Hck stoichiometrically phosphorylated at the C-terminal regulatory tyrosine.}


Since $\mathrm{Fe}^{3+}$ ions can bind to $\mathrm{pY}^{508}$-LynC and $\mathrm{pY}^{530}-\mathrm{SrcC}$, it is logical to predict that $\mathrm{Fe}^{3+}$ ions might perturb the inactive conformation of the SFKs by binding to the phosphorylated C-terminal regulatory tyrosine. To test this hypothesis, Lyn was co-expressed with the recombinant C-terminal Src Kinase CSK in insect cells, and stoichiometrically phosphorylated inactive $\mathrm{pY}^{508}$-Lyn was separated from the active unphosphorylated form of Lyn by passage of the partially purified enzyme preparation through a pYEEI column as described previously [21]. Western blot analysis confirmed that the protein in the $\mathrm{pY}^{508}$-Lyn preparation reacted strongly with the anti-Lyn-pY $\mathrm{Y}^{508}$ antibody, while the unphosphorylated Lyn exhibited no detectable reactivity with this antibody (Figure 6A). To confirm that the inactive $\mathrm{pY}^{508}$-Lyn preparation contains Lyn protein molecules that adopt the inactive conformation stabilised by intramolecular interactions between $\mathrm{pY}^{508}$ and the $\mathrm{SH} 2$ domain, the affinities of $\mathrm{pY}^{508}$-Lyn and unphosphorylated Lyn for the pYEEI peptide immobilised on the sensor chip were measured by surface plasmon resonance (Table 3). The unphosphorylated Lyn bound to the immobilised pYEEI peptide with high affinity $(71 \mathrm{nM})$ (Figure 6B), while $\mathrm{pY}^{508}$-Lyn exhibited lower affinity $(196 \mathrm{nM})$ towards the phosphopeptide. The data indicates that the accessibility of the SH2 domain of $\mathrm{pY}^{508}$-Lyn is lower that of the SH2 domain of unphosphorylated Lyn. Presumably, the intramolecular $\mathrm{pY}^{508}$-SH2 domain interactions reduce the accessibility of the $\mathrm{SH} 2$ domain to the exogenous phosphopeptide.

Addition of ferric ions enhanced the activity of $\mathrm{pY}^{508}$-Lyn (Figure 6C). The activity of $\mathrm{pY}^{508}$ Lyn was increased by $250 \%$ by addition of $80 \mu \mathrm{M}$ ferric ions. The observed enhancement of kinase activity of $\mathrm{pY}^{508}$-Lyn by $\mathrm{Fe}^{3+}$ ions is consistent with the hypothesis that binding of $\mathrm{Fe}^{3+}$ ions to phosphorylated $\mathrm{Y}^{508}$ disrupts its intramolecular interactions with the SH2 domain and hence enhances the kinase activity of $\mathrm{pY}^{508}$-Lyn. Although the addition of ferric ions increased the Biacore signal from $\mathrm{pY}^{508}$-Lyn, as would have been expected if the ferric ions were binding to phosphorylated $\mathrm{Y}^{508}$ and 
thereby increasing the open and active conformation of Lyn, a similar increase was observed with unphosphorylated Lyn (data not shown).

Among the Src-family members, Lyn exhibits the highest degree of sequence homology to Hck. For example, the sequences of the C-terminal segments of Lyn and Hck differ only by one residue Gly-506 of Lyn is replaced by Ser-520 at the homologous position in Hck. This high degree of sequence homology prompted us to examine the effect of ferric ions on the kinase activity of Hck with its C-terminal tail tyrosine (Tyr-522) stoichiometrically phosphorylated (pY ${ }^{522}$-Hck) (Figure 7A). Similar to the effect on $\mathrm{pY}^{508}$-Lyn, ferric ions induce a significant increase in kinase activity of $\mathrm{pY}^{522}$ Hck (Figure 7B). For example, the activity of $\mathrm{pY}^{522}$-Hck was increased by $560 \%$ by the addition of 80 $\mu \mathrm{M}$ of ferric ions.

In contrast, the activity of the unphosphorylated forms of Lyn (Figure 6D) and Hck (Figure 7B) in the presence of $80 \mu \mathrm{M}$ ferric ions was reduced by $59 \%$ and $34 \%$, respectively One possible explanation for the observed decrease in the activity of the unphosphorylated enzymes is that $\mathrm{Fe}^{3+}$ ions may compete for the $\mathrm{Mg}^{2+}$ binding site of ATP and hence reduce the amount of $\mathrm{Mg}$-ATP available for the kinase reaction. This notion is further supported by our observation that increasing concentrations of ferric ions reduce the activity of the isolated kinase domain of Hck, by over $50 \%$ at a ferric ion concentration of $80 \mu \mathrm{M}$ (Supplementary Fig. S1). Since the isolated kinase domain of Hck lacks the phosphorylated C-terminal tail tyrosine to which the ferric ions can bind, the effect of ferric ions on the kinase activity can only be exerted directly on the kinase domain, presumably by reducing the amount of $\mathrm{Mg}^{2+}-\mathrm{ATP}$. Because of the likely confounding effect on activity of the binding of $\mathrm{Fe}^{3+}$ ions to the $\mathrm{Mg}^{2+}$ binding site of ATP, no attempt was made to determine in more detail the effect of $\mathrm{Fe}^{3+}$ ions on the kinetic parameters of the kinase reaction for the phosphorylated forms of Lyn or Hck. 


\section{Discussion}

The data presented in this paper indicate that peptides derived from the C-terminus of the tyrosine kinase Src bind metal ions. The unmodified SrcC peptide binds two $\mathrm{Fe}^{3+}$ ions with affinities of 33 and $252 \mu \mathrm{M}$, and tyrosine phosphorylation increases the affinities by more than 10 -fold to 1.4 and $23 \mu \mathrm{M}$. The selective precipitation of the $\mathrm{pY}^{530}$-SrcC peptide observed in NMR experiments at $\mathrm{pH} 4.0$ is also consistent with our previous conclusion $[4,5]$ that tyrosine phosphorylation of peptides enhances the binding of $\mathrm{Fe}^{3+}$ ions. Although direct measurement of $\left[\mathrm{Ca}^{2+}\right]$ did not reveal evidence of binding of $\mathrm{Ca}^{2+}$ ions to any of the SrcC peptides (data not shown), the reduction in absorbance observed when a 5-fold excess of $\mathrm{Ca}^{2+}$ ions was added before the addition of $\mathrm{Fe}^{3+}$ ions (Figures 4A, 4D) suggests that $\mathrm{Ca}^{2+}$ does interact weakly with the $\mathrm{pY}^{530}-\mathrm{SrcC}$ peptide. The data with $\mathrm{Zn}^{2+}$ ions support a similar conclusion (Figures 4B, 4E), while with $\mathrm{Bi}^{3+}$ ions the excellent fit of the data at $\mathrm{pH} 6.5$ to a one-site model (Figure $4 \mathrm{~F}$ ) suggests that the binding of one $\mathrm{Bi}^{3+}$ ion to the $\mathrm{pY}^{530}$-SrcC peptide was stronger than the binding of the first $\mathrm{Fe}^{3+}$ ion.

The data presented herein also support the hypothesis that kinases of the Src family may be regulated by metal ions in vitro. The activity of Src family members is controlled by modification of the C-terminal regulatory tyrosine (referred to as $\mathrm{Y}_{\mathrm{T}}$ ) (Figure 8A) which, when phosphorylated, binds to the $\mathrm{SH} 2$ domain at the $\mathrm{N}$-terminus of the same molecule with consequent disruption of the active site $[11,12]$. The interactions between the $\mathrm{pY}^{530}-\mathrm{SrcC}$ peptide and metal ions described above are consistent with the suggestion that binding of $\mathrm{Fe}^{3+}$ ions to the phosphorylated $\mathrm{Y}_{\mathrm{T}}$ of Src might disrupt the intramolecular interaction with the $\mathrm{SH} 2$ domain and hence enhance kinase activity (Figure 8B). The kinase activity of purified preparations of the phosphorylated forms of Lyn (Figure 6C) or Hck (Figure 7B) in the presence of ferric ions showed a 250 or $560 \%$ enhancement, respectively. In contrast the activity of the purified unphosphorylated form of Lyn (Figure 6D) or Hck (Figure 7B) in the presence of ferric ions was reduced by 59 or $34 \%$, respectively, presumably because of binding of $\mathrm{Fe}^{3+}$ ions to 
the $\mathrm{Mg}^{2+}$ binding site of ATP [27]. Thus, the actual effect of the interaction between $\mathrm{Fe}^{3+}$ ions on the activity of the phosphorylated form of Lyn or Hck may well be greater, because competition for ATP by $\mathrm{Fe}^{3+}$ ions would be expected to reduce activity simultaneously. Because the activity of the unphosphorylated forms of Lyn and Hck is substantially higher than the activity of the corresponding phosphorylated form, it may be argued that the effect of ferric ions on the total Lyn (or Hck) activity will be minimal. However the critical question here is the relative amount of Lyn (or Hck) in the less active phosphorylated form. It is well established that in normal cells, the majority of SFKs such as Src, Hck and Lyn are kept in the inactive state by phosphorylation of the conserved C-terminal tail tyrosine [28]. Thus, binding of ferric ions will have a substantial effect on total activity. Relevant to this, we previously discovered that the specific activity of the SFK member Src in breast cancer cells is 2-5.6fold higher than that of Src expressed in normal fibroblasts. Furthermore, Muthuswamy, et al. found that the specific activity of Src in mammary tumour is $\sim 6.7$-fold higher than that of Src expressed in the adjacent mammary epithelium. Since Src protein molecules in normal fibroblasts and epithelial cells are mostly kept in the closed inactive conformation (Fig. 8A), the 2- 6.7-fold increase in Src specific activity is sufficient to contribute to tumorigenicity of breast cancer. Thus, our finding that ferric ions could increase the activity of $\mathrm{pY}^{508}$-Lyn and $\mathrm{pY}^{522}$-Hck by 2.5-6.6 folds is in agreement with the level of SFKs in cancer cells. It also implies that the activation of SFKs by ferric ions can have potential physiological impacts.

Little evidence exists in the literature for or against the hypothesis that kinases of the Src family are regulated by metal ions in vivo. On the one hand, in patients with the iron overload disease hereditary haemochromatosis, the tyrosine kinase activity of the CD8-associated Lck was significantly reduced compared to healthy controls [29]. On the other hand, in a subsequent in vitro study by the same authors, treatment of peripheral blood T-lymphocytes with ferric citrate reduced the amount of Lck associated with CD4, with a consequent decrease in the kinase activity of the CD4-associated Lck, 
but had no effect on the kinase activity of the CD8-associated Lck [30]. The concentration of the labile iron pool in lymphocytes from healthy humans is $0.57 \pm 0.27 \mu \mathrm{M}$ [31], and in cultured rat hepatocytes $5.4 \pm 1.3 \mu \mathrm{M}[32]$. Hence the concentration of the labile iron pool in lymphocytes from iron-overloaded individuals may well reach sufficiently high values to affect Lyn activity (Figure 6C).

SFKs may in some cases be involved in iron homeostasis. Drakesmith and coworkers have reported that down-regulation of the hemochromatosis protein HFE by the HIV-1 accessory protein Nef is responsible for the accumulation of iron in HIV-1-infected macrophages [33]. Furthermore, this effect of Nef requires the PxxP motif, which binds to the SH3 domain of Hck and Lyn to induce their activation [34]. Since Hck and Lyn are expressed in macrophages and participate in macrophage functions such as phagocytosis, it is likely that the Nef-activated Hck and/or Lyn contribute to downregulation of $\mathrm{HFE}$ in the infected macrophages. Given that $\mathrm{Fe}^{3+}$ ions can directly bind to the phosphorylated C-terminal tyrosine to induce activation of Hck and Lyn (Figures 6 and 7), it is possible that both Nef and the high concentration of $\mathrm{Fe}^{3+}$ ions cooperate to cause aberrant activation of Hck and/or Lyn in HIV-1-infected macrophages.

Iron uptake into neurons can stimulate generation of reactive oxygen species (ROS) and in turn modify the intracellular concentrations of reduced and oxidized glutathione [35]. In addition, iron uptake also leads to an increase in the labile iron pool in neurons [36]. Reactive oxygen species have been reported to activate the Src-family member Src by oxidation of Cys ${ }^{245}$ and/or Cys ${ }^{487}$ [37]. In contrast a recent report indicates that some SFKs may be inactivated by oxidation of Cys ${ }^{280}$ [38]. Formation of a disulfide bridge results in homodimerisation and up to a $90 \%$ loss of activity. The results presented in Figures 6 and 7 suggest an alternative mechanism, independent of reactive oxygen species, by which ferric ions may control the activity of the Src-family kinases Lyn and Hck.

In summary, the data presented herein establish that peptides derived from the C-terminus of the tyrosine kinases Src and Lyn bind $\mathrm{Fe}^{3+}$ ions, and that binding to the Src peptide at $\mathrm{pH} 4.0$ is enhanced 
by phosphorylation of $\mathrm{Y}^{530}$. The observation that the kinase activity of the phosphorylated forms of Lyn or Hck is significantly greater in the presence of $\mathrm{Fe}^{3+}$ ions than in their absence is consistent with the hypothesis that binding of $\mathrm{Fe}^{3+}$ ions to the phosphorylated C-terminal tyrosine of SFKs disrupts the intramolecular interaction with the $\mathrm{SH} 2$ domain and hence enhances kinase activity. These observations lay the biochemical foundation for future investigation of the regulation of Src family kinases by metal ions. Moreover our discoveries suggest that the intracellular effects of $\mathrm{Fe}^{3+}$ ions may be mediated by direct activation of signalling pathways as well as by the generation of reactive oxygen species. 


\section{Acknowledgements}

We thank Professor Greg Anderson of the Queensland Institute of Medical Research for many helpful discussions. This work was supported in part by grants from the National Health and Medical Research Council of Australia (400062, 454322; GB; 575502, RN; 509115, HC). The funders had no role in study design, data collection and analysis, decision to publish, or preparation of the manuscript. 


\section{Figure legends}

\section{Figure 1: Sequences of peptides used.}

The SrcC peptide corresponded to residues 523 - 536 of the human Src kinase sequence, with phenylalanine $\left(\mathrm{F}^{530}-\mathrm{SrcC}\right)$, tyrosine $\left(\mathrm{Y}^{530}-\mathrm{SrcC}\right)$ or phosphotyrosine $\left(\mathrm{pY}^{530}-\mathrm{SrcC}\right)$ at position 530 . The LynC peptide corresponded to residues 500 - 512 of the human Lyn kinase sequence, with the tyrosine at position 501 replaced by phenylalanine; the corresponding sequence in Hck is identical except for the replacement of the glycine at position 506 by serine. Sequences are shown in the one letter amino acid code.

\section{Figure 2: Phosphorylation enhances the binding of ferric ions to Src peptides.}

At $\mathrm{pH} 4.0$ (A), addition of aliquots of ferric chloride to $40 \mu \mathrm{M} \mathrm{pY}{ }^{530}-\mathrm{SrcC}(\bigcirc$, solid line) in $10 \mathrm{mM}$ $\mathrm{Na}^{+}$acetate, $100 \mathrm{mM} \mathrm{NaCl}, 0.005 \%$ Tween 20, 0.4\% DMSO, $298 \mathrm{~K}$ resulted in an increase in the absorption at $275 \mathrm{~nm}$. The change in absorption was much smaller on addition of aliquots of $\mathrm{FeCl}_{3}$ to $40 \mu \mathrm{M} \mathrm{Y}{ }^{530}-\operatorname{SrcC}(\boldsymbol{\Delta}$, dashed line $)$ or $\mathrm{F}^{530}-\operatorname{SrcC}(\boldsymbol{\nabla}$, dotted line $)$. At $\mathrm{pH} 6.5$ (B) in $10 \mathrm{mM} \mathrm{Na}^{+}$PIPES, $100 \mathrm{mM} \mathrm{NaCl}, 0.005 \%$ Tween 20, 0.4\% DMSO, an increase in absorption at $275 \mathrm{~nm}$ was observed on addition of ferric chloride to $\mathrm{pY}^{530}-\mathrm{SrcC}, \mathrm{Y}^{530}-\mathrm{SrcC}$, or $\mathrm{F}^{530}-\mathrm{SrcC}$, but the increase was greatest with $\mathrm{pY}^{530}$-SrcC. Data are expressed as the change in absorbance of that peptide from the value observed in the absence of ferric ions. Points are means of at least three separate experiments; bars represent the SEM. Lines represent the best fit to a two-site model with the program BioEqs; the appropriate $\mathrm{K}_{\mathrm{d}}$ values are given in Table 1.

\section{Figure 3: Ferric ions precipitate the phosphorylated Src peptide.}

At pH 4.0 and $298 \mathrm{~K}$ addition to $50 \mu \mathrm{M} \mathrm{Y}^{530}-\mathrm{SrcC}$ (A) of 1 (spectrum II) or $2 \mathrm{~mol} / \mathrm{mol}$ (spectrum III) of $\mathrm{FeCl}_{3}$ resulted in small reductions in signal intensity and some general line broadening due to the presence of paramagnetic ferric ions in solution compared to the spectrum without ferric ions (spectrum 
I). In contrast, addition of ferric ions to $\mathrm{pY}^{530}-\mathrm{SrcC}(\mathrm{B})$ resulted in a substantial loss of signal intensity. These results indicate the formation of insoluble $\mathrm{Fe}^{3+}$-peptide complexes over the duration of the NMR experiment. No appreciable shifts in resonances were observed for either peptide remaining in solution after addition of ferric ions. At pH 6.5 addition of Fe citrate to $\mathrm{Y}^{530}-\mathrm{SrcC}$ at 2 (spectrum II) or 10 $\mathrm{mol} / \mathrm{mol}$ (spectrum III) caused only general broadening and intensity changes (C). Addition of Fe citrate to $\mathrm{pY}^{530}-\mathrm{SrcC}$ caused a downfield shift in the arrowed G11 NH resonance (D).

\section{Figure 4: Binding of ferric ions to SrcPY is not greatly affected by other metal ions.}

Addition of aliquots of calcium chloride $(\mathrm{A}, \mathrm{D}, \mathbf{\Delta})$ zinc sulfate $(\mathrm{B}, \mathrm{E}, \boldsymbol{\nabla})$ or bismuth nitrate $(\mathrm{C}, \mathrm{F}, \mathbf{\square})$ to $40 \mu \mathrm{M} \mathrm{pY}{ }^{530}-\mathrm{SrcC}$ at $\mathrm{pH} 4.0(\mathrm{~A}, \mathrm{~B}, \mathrm{C})$ or $\mathrm{pH} 6.5(\mathrm{D}, \mathrm{E}, \mathrm{F})$ did not result in any increase in the absorbance at $275 \mathrm{~nm}$ up to a molar ratio of 5. Subsequent addition of aliquots of ferric chloride to the solutions containing calcium $(\triangle$, solid line) or zinc ( $\nabla$, solid line) resulted in increases in absorbance that were similar to the increase seen when ferric ions were added to $\mathrm{pY}^{530}-\mathrm{SrcC}$ in the absence of calcium or zinc ions $(\boldsymbol{O}$, dotted line). In contrast when aliquots of ferric chloride were added to the solution containing bismuth ( $\square$, solid line) at $\mathrm{pH} 6.5$ the increase in absorbance differed from that seen when ferric ions were added to $\mathrm{pY}^{530}-\mathrm{SrcC}$ in the absence of bismuth ions ( $\boldsymbol{O}$, dotted line). Points are means of at least three separate experiments; bars represent the SEM. The lines represent the best fits to a two-site ordered model with the program BioEqs, with the exception of E, where a one-site model fitted the data well. The $\mathrm{K}_{\mathrm{d}}$ and $\mathrm{A}_{275}$ values for the lines of best fit are given in Table 1 .

\section{Figure 5: Binding of ferric ions to the Lyn peptide.}

Addition of aliquots of ferric chloride to $40 \mu \mathrm{MpY}^{530}-\operatorname{SrcC}(\Theta$, solid line) at $\mathrm{pH} 4.0$ (A) resulted in an increase in the absorption at $275 \mathrm{~nm}$. The change in absorption was greater on addition of aliquots of $\mathrm{FeCl}_{3}$ to $40 \mu \mathrm{M}$ phosphorylated LynC ( $\square$, dotted line). At pH 6.5 (B) the increase in absorption at 275 
$\mathrm{nm}$ after addition of ferric chloride to phosphorylated LynC ( $\square$, dotted line) was again greater than to $\mathrm{pY}^{530}$-SrcC (O, solid line), but the data was no longer well fitted by a two-site model. Data are expressed as the change in absorbance of that peptide from the value observed in the absence of ferric ions. Points are means of at least three separate experiments; bars represent the SEM. Lines represent the best fit to a two-site model with the program BioEqs; the appropriate $K_{d}$ and $A_{275}$ values values are given in Table 1.

\section{Figure 6: Ferric ions enhance the activity of C-terminally phosphorylated Lyn.}

The phosphorylation status of the C-terminally phosphorylated Lyn ( $\mathrm{pY}^{508}$-Lyn) and unphosphorylated Lyn $\left(0.5 \mu \mathrm{g}\right.$ each) used in the activity assay was analysed by Western blot (A), with anti-pY ${ }^{508}$-Lyn and anti-Lyn antibodies. The unphosphorylated Lyn preparation contained a small amount of degraded Lyn protein which can be recognized by the anti-Lyn antibody (*). Accessibility of the SH2 domain of $\mathrm{pY}^{508}$-Lyn $(1,410 \mathrm{nM})$ and unphosphorylated Lyn $(700 \mathrm{nM})$ to the exogenous pYEEI peptide was monitored by binding of the two proteins to the pYEEI peptide immobilised on a sensor chip (B). The binding response was recorded for about 250 seconds, at which point (arrow) the surface was washed with HEPES-buffered saline to induce dissociation. The corresponding signal obtained when the sample was injected over a blank-derivatized control channel was subtracted to obtain the sensorgrams shown. The kinetic parameters of binding to the immobilized phosphopeptide are presented in Table 3. The specific activities of $\mathrm{pY}^{508}$-Lyn $(\mathrm{O})$ and unphosphorylated Lyn $(O)(\mathrm{C}$ and $\mathrm{D})$ in the presence of increasing concentrations of ferric ions were determined as described in Materials and Methods. The amounts of enzymes used in the assay were: $\mathrm{pY}^{508}$-Lyn: $0.74 \mu \mathrm{g}$ and Lyn: $0.13 \mu \mathrm{g}$. Points are means of at least three separate experiments; bars represent the SEM. Statistical significance relative to the control without ferric ions was assessed by one-way ANOVA with Bonferroni correction: **, $P<0.01$; 
\#, $P<0.001$. The phosphorylated form of Lyn was activated, and the unphosphorylated form inhibited, by ferric ions.

Figure 7: Ferric ions enhance the activity of C-terminally phosphorylated Hck.

The phosphorylation status of C-terminally phosphorylated Hck ( $\mathrm{pY}^{522}$-Hck), and unphosphorylated Hck (6 ng each) used in the activity assay was analysed by Western blot (A). The specific activities of C-terminally phosphorylated $(\mathrm{O})$ and unphosphorylated $(\bullet)$ forms of Hck in the presence of increasing concentrations of ferric ions (B) were determined as described in Materials and Methods. The amounts of enzymes used in the assay were: $\mathrm{pY}^{522}$-Hck: $30 \mathrm{ng}$; Hck: $90 \mathrm{ng}$. Points are means of at least three separate experiments; bars represent the SEM. Statistical significance relative to the control without ferric ions was assessed by one-way ANOVA with Bonferroni correction: **, $P<0.01$; ${ }^{\#}, P<0.001$. The phosphorylated form of Hck was activated, and the unphosphorylated form inhibited, by ferric ions.

\section{Figure 8: A model depicting how SFKs are activated by binding of $\mathrm{Fe}^{3+}$ ions.}

(A) SFKs such as c-Src are stabilized in an inactive conformation (PDB ID: 2SRC) by two types of intramolecular interactions: (i) the interaction between the phosphorylated C-terminal regulatory tyrosine ( $\mathrm{pY}_{\mathrm{T}}$ corresponding to $\mathrm{pY}^{503}$ of human c-Src) and the SH2 domain, and (ii) the interactions between the SH2-kinase linker and the SH3 domain. The left panel depicts a close-up view of the Cterminal tail of c-Src bound to the $\mathrm{SH} 2$ domain. $\mathrm{Q}^{529}, \mathrm{pY}^{530}, \mathrm{Q}^{531}, \mathrm{P}^{532}$ and $\mathrm{G}^{533}$ in the C-terminal tail segment (EPQpYQPGENL) are shown. (B) Models of the structures of active and inactive forms of SFKs are shown. In addition to the $\mathrm{SH} 3, \mathrm{SH} 2$ and kinase domains and the C-terminal tail, the Nterminal unique domain (dotted line) linked to the SH3 domain is shown. In the absence of $\mathrm{Fe}^{3+}$ ions (B), the phosphorylated $\mathrm{Y}_{\mathrm{T}}$ transiently dissociates from the $\mathrm{SH} 2$ domain. The dissociation allows the 
SFK molecule to adopt an active conformation and hence contributes to the basal activity exhibited by SFKs in the inactive conformation in vitro (e.g. by $\mathrm{pY}^{508}$-Lyn and $\mathrm{pY}^{522}$-Hck at $0 \mu \mathrm{M} \mathrm{Fe}^{3+}$ ions in Figures 6 and 7, respectively). If present, $\mathrm{Fe}^{3+}$ ions bind to $\mathrm{pY}_{\mathrm{T}}$ once it has dissociated from the SH2 domain. The binding prevents the association of $\mathrm{pY}_{\mathrm{T}}$ with the $\mathrm{SH} 2$ domain and thus stabilizes the SFK in the active conformation, with a consequent increase in activity. Presumably, the $\mathrm{Fe}^{3+}$-bound $\mathrm{pY}_{\mathrm{T}^{-}}$ SFK can be activated further by autophosphorylation at the consensus tyrosine in the activation loop of the kinase domain. 
Table 1: Binding of Ferric Ions by Src and Lyn Peptides.

\begin{tabular}{|c|c|c|c|c|}
\hline & \multicolumn{2}{|l|}{$\begin{array}{l}\text { Ferric ions } \\
\text { pH } 4.0\end{array}$} & \multicolumn{2}{|c|}{$\begin{array}{l}\text { Ferric ions } \\
\text { pH } 6.5\end{array}$} \\
\hline & $\mathrm{K}_{\mathrm{d}}(\mu \mathrm{M})$ & $\mathrm{A}_{275}$ & $\mathrm{~K}_{\mathrm{d}}(\mu \mathrm{M})$ & $\mathrm{A}_{275}$ \\
\hline $\mathrm{F}^{530}-\mathrm{SrcC}$ unoccupied & - & 0.0041 & - & 0.0011 \\
\hline $1^{\text {st }}$ site & 0.30 & 0.0267 & 0.001 & 0.0045 \\
\hline $2^{\text {nd }}$ site & 60 & 0.0107 & 452 & 0.0988 \\
\hline $\mathrm{Y}^{530}$-SrcC unoccupied & - & 0.0450 & - & 0.0508 \\
\hline $1^{\text {st }}$ site & 33 & 0.0885 & 1.0 & 0.0508 \\
\hline $2^{\text {nd }}$ site & 252 & 0.0305 & 108 & 0.1547 \\
\hline $\mathrm{pY}^{530}-\mathrm{SrcC}$ unoccupied & - & 0.0158 & - & 0.0249 \\
\hline $1^{\text {st }}$ site & 1.4 & 0.0334 & 4.0 & 0.0189 \\
\hline $2^{\text {nd }}$ site & 23 & 0.1599 & 49 & 0.1939 \\
\hline pY ${ }^{508}$-LynC unoccupied & - & 0.0262 & - & 0.0416 \\
\hline $1^{\text {st }}$ site & $1.2 \times 10^{-6}$ & 0.1130 & 1.6 & 0.0266 \\
\hline $2^{\text {nd }}$ site & 0.16 & 0.1677 & 301 & 1.1308 \\
\hline
\end{tabular}

The affinity of ferric ion binding to $\mathrm{F}^{530}-\mathrm{SrcC}, \mathrm{Y}^{530}-\mathrm{SrcC}, \mathrm{pY}^{530}-\mathrm{SrcC}$ or $\mathrm{pY}^{508}-\mathrm{LynC}$, and the absorbance of each peptide at $275 \mathrm{~nm}$ with 0,1 or 2 ferric ion binding sites occupied, were determined by fitting the mean data obtained in the absorbance experiments described in the Figure 2 and 5 legends with the program BioEqs. 
Table 2: Effect of Other Metal Ions on the Binding of Ferric Ions by the SrcC Peptide.

\begin{tabular}{|c|c|c|c|c|c|}
\hline \multirow[t]{2}{*}{ Other metal ion } & & \multicolumn{2}{|c|}{$\begin{array}{l}\text { Ferric ions } \\
\mathrm{pH} 4.0\end{array}$} & \multicolumn{2}{|c|}{$\begin{array}{l}\text { Ferric ions } \\
\text { pH } 6.5\end{array}$} \\
\hline & & $\mathrm{K}_{\mathrm{d}}(\mu \mathrm{M})$ & $\Delta \mathrm{A}_{275}$ & $\mathrm{~K}_{\mathrm{d}}(\mu \mathrm{M})$ & $\Delta \mathrm{A}_{275}$ \\
\hline \multirow[t]{2}{*}{ None } & $1^{\text {st }}$ site & 1.4 & 0.0176 & 4.0 & 0.0 \\
\hline & $2^{\text {nd }}$ site & 23 & 0.1441 & 49 & 0.1690 \\
\hline \multirow[t]{2}{*}{$\mathrm{Ca}^{2+}$} & $1^{\mathrm{st}}$ site & 4.3 & 0.0102 & 0.5 & 0.0136 \\
\hline & $2^{\text {nd }}$ site & 12 & 0.1076 & 13 & 0.0879 \\
\hline \multirow[t]{2}{*}{$\mathrm{Zn}^{2+}$} & $1^{\text {st }}$ site & 2.6 & 0.0314 & $1.3 \times 10^{-5}$ & 0.0199 \\
\hline & $2^{\text {nd }}$ site & 15 & 0.1218 & 16 & 0.0764 \\
\hline \multirow[t]{2}{*}{$\mathrm{Bi}^{2+}$} & $1^{\text {st }}$ site & 2.4 & 0.0320 & 0.19 & 0.0477 \\
\hline & $2^{\text {nd }}$ site & 16 & 0.1122 & - & - \\
\hline
\end{tabular}

The apparent affinity of ferric ion binding to the $\mathrm{pY}^{530}$-SrcC peptide and the change in absorbance at $275 \mathrm{~nm}$ after occupation of 1 or 2 ferric ion binding sites, alone or in the presence of $200 \mu \mathrm{M} \mathrm{Ca}^{2+}$, $\mathrm{Zn}^{2+}$ or $\mathrm{Bi}^{2+}$ ion, were determined by fitting the mean data obtained in the absorbance experiments described in the Figure 4 legend with the program BioEqs. 
Table 3: Kinetic Parameters and Surface Binding activity for Binding of $\mathrm{pY}^{508}$-Lyn and Lyn to the pYEEI Peptide as Determined by Surface Plasmon Resonance.

\begin{tabular}{|c|c|c|c|c|c|c|c|}
\hline Enzyme & $\begin{array}{l}\text { Conc } \\
(\mathbf{n M})\end{array}$ & $\begin{array}{c}\text { Binding } \\
\text { signal } \\
(\mathrm{RU}) \\
\end{array}$ & SMBA & $\begin{array}{l}k_{a} \times 10^{-4} \\
\left(M^{-1} s^{-1}\right)\end{array}$ & $\begin{array}{c}k_{d} \times 10^{3} \\
\left(s^{-1}\right)\end{array}$ & $\begin{array}{c}\mathbf{K}_{\mathrm{D1}} \\
(\mathbf{n M})\end{array}$ & $\chi^{2}$ \\
\hline $\mathrm{pY}^{508}$-Lyn & 1410 & 27 & 0.0016 & 1.6 & 3.2 & 196 & 0.37 \\
\hline Lyn & 700 & 327 & 0.0193 & 3.4 & 2.4 & 71 & 1.28 \\
\hline
\end{tabular}

The immobilized pYEEI peptide gave a signal of 1272 resonance units (RU). SMBA, Surface Molar Binding Activity. 


\section{References}

[1] T. Pawson, Regulation and targets of receptor tyrosine kinases, Eur J Cancer. 38 Suppl 5 (2002) S3-10.

[2] P. Blume-Jensen, T. Hunter, Oncogenic kinase signalling, Nature. 411 (2001) 355-365.

[3] J.J.R.F.D. Silva, R.J.P. Williams, The Biological Chemistry of the Elements, Clarendon Press, Oxford, 1991.

[4] G.S. Baldwin, M.F. Bailey, B.P. Shehan, I. Sims, R.S. Norton, Tyrosine modification enhances metal-ion binding, Biochem J. 416 (2008) 77-84.

[5] G.S. Baldwin, Phosphorylation of cyclin-dependent kinase 2 peptides enhances metal binding, Biochem Biophys Res Commun. 379 (2009) 151-154.

[6] Z. Debebe, T. Ammosova, M. Jerebtsova, J. Kurantsin-Mills, X. Niu, S. Charles, D.R. Richardson, P.E. Ray, V.R. Gordeuk, S. Nekhai, Iron chelators ICL670 and 311 inhibit HIV-1 transcription, Virology. 367 (2007) 324-333.

[7] S.J. Parsons, J.T. Parsons, Src family kinases, key regulators of signal transduction, Oncogene. 23 (2004) 7906-7909.

[8] T.J. Boggon, M.J. Eck, Structure and regulation of Src family kinases, Oncogene. 23 (2004) 7918-7927.

[9] J.R. Engen, T.E. Wales, J.M. Hochrein, M.A. Meyn, 3rd, S. Banu Ozkan, I. Bahar, T.E. Smithgall, Structure and dynamic regulation of Src-family kinases, Cell Mol Life Sci. 65 (2008) 3058-3073.

[10] P. Scapini, S. Pereira, H. Zhang, C.A. Lowell, Multiple roles of Lyn kinase in myeloid cell signaling and function, Immunol Rev. 228 (2009) 23-40. 
[11] F. Sicheri, J. Kuriyan, Structures of Src-family tyrosine kinases, Curr Opin Struct Biol. 7 (1997) 777-785.

[12] R. Roskoski, Jr., Src kinase regulation by phosphorylation and dephosphorylation, Biochem Biophys Res Commun. 331 (2005) 1-14.

[13] H.C. Cheng, C.M. Litwin, D.M. Hwang, J.H. Wang, Structural basis of specific and efficient phosphorylation of peptides derived from $\mathrm{p} 34 \mathrm{cdc} 2$ by a pp60src-related protein tyrosine kinase, J Biol Chem. 266 (1991) 17919-17925.

[14] T.M. Johnson, J.W. Perich, J.D. Bjorge, D.J. Fujita, H.C. Cheng, Common and differential recognition of structural features in synthetic peptides by the catalytic domain and the Srchomology 2 (SH2) domain of pp60c-src, J Pept Res. 50 (1997) 365-371.

[15] C.A. Royer, W.R. Smith, J.M. Beechem, Analysis of binding in macromolecular complexes: a generalized numerical approach, Anal Biochem. 191 (1990) 287-294.

[16] C.A. Royer, Improvements in the numerical analysis of thermodynamic data from biomolecular complexes, Anal Biochem. 210 (1993) 91-97.

[17] J. Pannequin, K.J. Barnham, F. Hollande, A. Shulkes, R.S. Norton, G.S. Baldwin, Ferric ions are essential for the biological activity of the hormone glycine-extended gastrin, J Biol Chem. 277 (2002) 48602-48609.

[18] O. Park, H.E. Swaisgood, J.C. Allen, Calcium binding of phosphopeptides derived from hydrolysis of alpha s-casein or beta-casein using immobilized trypsin, J Dairy Sci. 81 (1998) 2850-2857.

[19] Y.P. Chong, A.S. Chan, K.C. Chan, N.A. Williamson, E.C. Lerner, T.E. Smithgall, J.D. Bjorge, D.J. Fujita, A.W. Purcell, G. Scholz, T.D. Mulhern, H.C. Cheng, C-terminal Src kinasehomologous kinase (CHK), a unique inhibitor inactivating multiple active conformations of Src family tyrosine kinases, J Biol Chem. 281 (2006) 32988-32999. 
[20] R.J. Sicilia, M.L. Hibbs, P.A. Bello, J.D. Bjorge, D.J. Fujita, I.J. Stanley, A.R. Dunn, H.C. Cheng, Common in vitro substrate specificity and differential Src homology 2 domain accessibility displayed by two members of the Src family of protein-tyrosine kinases, c-Src and Hck, J Biol Chem. 273 (1998) 16756-16763.

[21] N. Sotirellis, T.M. Johnson, M.L. Hibbs, I.J. Stanley, E. Stanley, A.R. Dunn, H.C. Cheng, Autophosphorylation induces autoactivation and a decrease in the Src homology 2 domain accessibility of the Lyn protein kinase, J Biol Chem. 270 (1995) 29773-29780.

[22] T.M. Johnson, N.A. Williamson, G. Scholz, A. Jaworowski, R.E. Wettenhall, A.R. Dunn, H.C. Cheng, Modulation of the catalytic activity of the Src family tyrosine kinase Hck by autophosphorylation at a novel site in the unique domain, J Biol Chem. 275 (2000) 3335333364.

[23] H.C. Cheng, J.D. Bjorge, R. Aebersold, D.J. Fujita, J.H. Wang, Purification of bovine thymus cytosolic C-terminal Src kinase (CSK) and demonstration of differential efficiencies of phosphorylation and inactivation of p561yn and pp60c-src by CSK, Biochemistry. 35 (1996) 11874-11887.

[24] B. Catimel, M. Nerrie, F.T. Lee, A.M. Scott, G. Ritter, S. Welt, L.J. Old, A.W. Burgess, E.C. Nice, Kinetic analysis of the interaction between the monoclonal antibody A33 and its colonic epithelial antigen by the use of an optical biosensor. A comparison of immobilisation strategies, J Chromatogr A. 776 (1997) 15-30.

[25] E.C. Nice, B. Catimel, Instrumental biosensors: new perspectives for the analysis of biomolecular interactions, Bioessays. 21 (1999) 339-352.

[26] R. Hoffmann, I. Reichert, W.O. Wachs, M. Zeppezauer, H.R. Kalbitzer, 1H and 31P NMR spectroscopy of phosphorylated model peptides, Int J Pept Protein Res. 44 (1994) 193-198. 
[27] W.J. O'Sullivan, Stability Constants of Metal Complexes, in: R.M.C. Dawson, Elliott, D.C., Elliott, W.H., Jones, K.M. (Ed.), Data for Biochemical Research

Oxford University Press, Oxford, 1969, pp. 423-434.

[28] J.D. Bjorge, A. Jakymiw, D.J. Fujita, Selected glimpses into the activation and function of Src kinase, Oncogene. 19 (2000) 5620-5635.

[29] F.A. Arosa, A.J. da Silva, I.M. Godinho, J.C. ter Steege, G. Porto, C.E. Rudd, M. de Sousa, Decreased CD8-p56lck activity in peripheral blood T-lymphocytes from patients with hereditary haemochromatosis, Scand J Immunol. 39 (1994) 426-432.

[30] F.A. Arosa, M. de Sousa, Iron differentially modulates the CD4-lck and CD8-lck complexes in resting peripheral blood T-lymphocytes, Cell Immunol. 161 (1995) 138-142.

[31] Y. Ma, Z. Liu, R.C. Hider, F. Petrat, Determination of the labile iron pool of human lymphocytes using the fluorescent probe, CP655, Anal Chem Insights. 2 (2007) 61-67.

[32] Y. Ma, H. de Groot, Z. Liu, R.C. Hider, F. Petrat, Chelation and determination of labile iron in primary hepatocytes by pyridinone fluorescent probes, Biochem J. 395 (2006) 49-55.

[33] H. Drakesmith, N. Chen, H. Ledermann, G. Screaton, A. Townsend, X.N. Xu, HIV-1 Nef down-regulates the hemochromatosis protein HFE, manipulating cellular iron homeostasis, Proc Natl Acad Sci U S A. 102 (2005) 11017-11022.

[34] R.P. Trible, L. Emert-Sedlak, T.E. Smithgall, HIV-1 Nef selectively activates Src family kinases Hck, Lyn, and c-Src through direct SH3 domain interaction, J Biol Chem. 281 (2006) 27029-27038.

[35] M.T. Nunez, V. Gallardo, P. Munoz, V. Tapia, A. Esparza, J. Salazar, H. Speisky, Progressive iron accumulation induces a biphasic change in the glutathione content of neuroblastoma cells, Free Radic Biol Med. 37 (2004) 953-960. 
[36] P. Munoz, A. Humeres, C. Elgueta, A. Kirkwood, C. Hidalgo, M.T. Nunez, Iron mediates Nmethyl-D-aspartate receptor-dependent stimulation of calcium-induced pathways and hippocampal synaptic plasticity, J Biol Chem. 286 (2011) 13382-13392.

[37] E. Giannoni, F. Buricchi, G. Raugei, G. Ramponi, P. Chiarugi, Intracellular reactive oxygen species activate Src tyrosine kinase during cell adhesion and anchorage-dependent cell growth, Mol Cell Biol. 25 (2005) 6391-6403.

[38] D.J. Kemble, G. Sun, Direct and specific inactivation of protein tyrosine kinases in the Src and FGFR families by reversible cysteine oxidation, Proc Natl Acad Sci U S A. 106 (2009) 50705075 . 